\title{
Study Visits as a Method of professional motivation formation in future choreographers
}

\author{
N. V. Tereshenko ${ }^{1}$, T. A. Medvid ${ }^{2}$, V. A. Grek ${ }^{3}$, T. H. Lugovenko ${ }^{4}$ \\ ${ }^{1}$ Kherson State University, Kherson, 27, Universytetska Str., Kherson, 73003, Ukraine \\ ${ }^{234}$ Borys Grinchenko Kyiv University, 18/2, Bulvarno-Kudriavska Str., Kyiv, 04053, Ukraine
}

Received: August 17, 2021. Revised: September 27, 2021. Accepted: September 30, 2021. Published: October 4, 2021.

\begin{abstract}
The article presents the results of the studying the effect of the study visits method on the formation of professional motivation in second-year students majoring in specialty 024 "Choreography". Group balancing was performed by random selection according to age, gender and levels of choreographic training. The experiment was conducted in accordance with the pattern "Before-after with the control group". The study visits method of famous choreographers was used to conduct master classes with students of the experimental group. Rean's technique (adapted by the author) is used to diagnose the students' level of professional motivation. Pearson's coefficient and $\chi 2$ Pearson's criterion were used to calculate the relationships between factor and result features, as well as to define the statistical significance of the data obtained. The study visits' motivational potential in the course of training future choreographers is revealed: in the experimental group in comparison with the control group there was a significant increase in motivation. The correlation between the growth of motivation and the increase of the level of the students' choreographic training is revealed. The analysis of students' essays was carried out, which established the content of students' motivational intentions for future professional activity. The role of transgression as a phenomenon of shaping the choreography students' motivation under the influence of encounters with artists is brought forward, which should be subject to further research.
\end{abstract}

Keywords: master classes, professional motivation, choreographic training, training motivation, methods of motivation.

\section{INTRODUCTION}

Currently, the understanding of the education quality includes a shift of pedagogical paradigm to elicit the most effective motivation means for professional activity with the view to the necessity to train a new generation of professionals. The focus on the motivational approach in the process of training students is expedient, as it emphasizes the innovative content and requires qualitative changes in the entire educational structure. When it comes to the specificity of choreographic art in the narrowest sense, it is common knowledge that in the kinesthetic (dance) performance, that is the ability to convey the author's ideological idea through the body and acting. However, choreographic education would be incomplete without teaching students the evolution of their basic creative abilities, pedagogical skills, as well as without teaching the skill of forming professional motivation. Thus, the training of a pedagogue in choreography involves the development of professional competencies in an integrated way - in the field of pedagogy as well as in the art of dance. Accordingly, the professional tasks of choreographic education are differentiated into general didactic and specific. The formation of motivation to comprehensive training includes both tasks of training future choreographers.

A significant factor in enhancing the quality of future choreographers' training is the students' professional motivation, which drives the individual to constant creative search and professional self-development. Drawing on their own teaching experience and analysis of practical aspects of the educational process, it can stand to reason that the best learning outcomes are achieved by students possessing a high level of motivation for future professional activities. Therefore, one of the major scientific issues of enhancing the future choreographers' quality of training is the search for powerful methods of shaping their professional motivation in the learning process at higher education institutions.

Analysis of relevant scientific publications shows a wide variety of approaches and methods of choreographers' professional training: from the general formulation of the problem: "How do dancers learn to dance?" [1], to a more focused view of specific techniques. For example, the dissertation of author [2] explores the relevance of classical modern dance techniques in the training of modern choreographers. Author [3] offers a four-step method of teaching choreography based on the method of ideokinesis 
(visualization of movement).

In the article by authors [4] the somatic principles' integration efficiency according to Feldenkrais Method and Hanna Somatics is investigated. Drawing on the results of the experiment, the students acquired the skills of getting to know each other and their partners they could better focus on personal development, as well as motivate themselves and improve their learning [4]. This method is also observed by author. [5]. Numerous authors pay attention to the moving mental images methods in teaching choreography $[6 ; 7 ; 8]$.

Another sought-after modern method of teaching choreography referred to as Gaga (developed by Ohad Nagarin), was explored in the article by author [9]. In this case, it is an integrated paradigm of choreography, technique and improvisation in the training of students, which inspires and promotes their professional development, expanding the range of skills and knowledge, freedom of will and creativity.

Still another framework of training and development of dancers and choreographers is considered by author [10] in his article. The author's method is based on bodily practices related to the "instant composition" proposed by the British choreographer J. Hamilton. The author conducted a field study of artistic practice, as a result of which she offers the technique of body work and choreographic training that encourage the evolvement of an autonomous body, inspire improvisation, composition while integrating time, music and space [10].

Pedagogical conditions for the formation of professional competence in future teachers of choreography on the basis of choreography art history materials of Kazakhstan are studied in the article by author [11]. To evaluate the results, the authors identified three criteria: the motivational and target criterion, the cognitive activity criterion, and the evaluative and effective criterion. According to the results of the experiment, the effectiveness of the proposed model was confirmed and scientific and methodological recommendations for the formation of professional competence in students of the choreographic profession were elaborated [11]. The pedagogical approach in the training of choreographers in higher educational institutions of Ukraine is also considered by author [12].

The application of the emotional intelligence theory in the training of future teachers of choreography is addressed in the article by author [13]. The study experimentally proved the effectiveness of the emotional intelligence impact on student self-efficacy. To increase the level of emotional intelligence of future dance teachers, the authors elborated specific development programs [13].

In modern pedagogical practice, in particular in the process of training choreographers, the use of electronic teaching aids and online education is becoming increasingly important. For example, the publication of author [14] hold that learning outcomes and motivation are largely influenced by blended methods, including the STEAM approach, in which researchers focus on combining software design and choreography. The results of the experiment demonstrate that, despite significant differences, students' motivation and learning outcomes tend to be increasing [14].

The influence of online education on the formation of subject and technical competencies of masters of choreography is studied by author [15]. Basically, the overriding finding of this research the author considers to be the development of future choreographers' system of competencies (personal traits, knowledge and skills), including the motivational component. According to the author, the results of the study are universal in their nature, and can be applied in both local and global management practices of choreographic education [15].

In some studies, choreography is considered as a method of developing certain qualities of specialists in other areas. For example, in the article by author [16] the results of the experiment are presented, which proves that under certain conditions (participation in master classes, application of engaging methods, use of creative tasks) choreography lessons urge in prospective music teachers the development of creative abilities and positive motivation to learn [16]. Furthermore, choreography is used as a method and as a metaphor for the study of the learning process and the teacher's individual style in their interaction with students [17]. We find a similar approach in the article by author [18], which contains the summing up of the author's reflections on dance and choreography as a method of perceiving one's own body and psycho-emotional sphere.

Author [19] publication considers the involvement in conducting master classes by guest choreographers and teachers. The author claims that this method is an integral part of students' ability to expand their knowledge and master new dancing styles and techniques, to improve their skills, to cultivate the motivation to succeed, to elicit energy and inspiration.

Colligating the publications related to the topic of our research, the inference can be made that each article we reviewed contains an element of novelty in teaching methods, in particular: the increase in body awareness and unpacking the body somatics [4], playing with body, space and base [9], "instant composition" regarding the development of the autonomous body [10]. In addition, the authors emphasize the involvement of external choreographers and teachers for workshops, the utilization of active learning methods [16; 19], the study of specific art materials in choreography [11], dance and choreography as a method of exploring own body and the personality's psycho-emotional sphere [18].

However, in the range of scientific publications addressed, the method of study visits which has a significant motivational potential for students, was left out of the researchers' attention. Instead, these methods are widely used in the curricula and practical work of many leading choreographic schools, such as the Northern School of Contemporary Dance in Chapetown, the University of Winchester School of Choreography and Dance, the Broadway Dance School, the Kanopy Dance Company and others $[20 ; 21]$. With this in mind, the purpose 
of our study is to experimentally test the motivational potential of the study visits method in training of future choreographers.

\section{METHODS}

To conduct an experiment, among the general population, which consisted of second-year students majoring in specialty 024 "Choreography", with a total number of 93 people, a sample of 75 students was formed using a method of randomization (confidence probability $\mathrm{p}=95 \%$, error margin $\Delta= \pm 0.05$ ). Next, an experimental group (EG) of 37 students and a control group (CG) of 38 students were formed from the sample. The group balancing was executed according to the following criteria: age, gender and levels of choreographic training.

The first stage of the experiment is ascertaining. The experimental work at this stage included:

- the study of the professional motivation process;

- the research of factors that may reflect the effectiveness of choreographers' professional motivation;

- the determination of the criterion under study;

- the preparation for the study.

The second stage of the pedagogical experiment is formative. At the formative stage, the content of the experimental work included:

- the elaboration the experimental work Program;

- the introduction of visit's pedagogical conditions as a professional motivation method;

- the control over the pedagogical experiment proceedings with the help of questionnaires;

- the analysis and processing of the experiment results obtained;

- the summing up of the pedagogical experiment results.

Stage III of the pedagogical experiment is summarizing. The content of this stage of the experiment included systematization and generalization of experimental work results, formulation of research conclusions.

The experiment was conducted according to the pattern "Before-after with the control group". To develop the professional motivation of EG students, the method of "guest" study visits was used, which presupposed invitations of famous teachers, ballet dancers, choreographers to conduct master classes in higher education institutions, during which students had the opportunity to learn about different learning styles and methods of choreography teaching, to carry out the comparative analysis, to build their own portfolio of pedagogical skills in choreography. The students were tasked to analyze the visits in terms of their practical significance for learning. The structure of the analysis is given in Appendix A. During that semester, the CG students studied according to the usual program without the use of study visits.

All the respondents were informed in advance about the requirement to give responses to questions independently and with utmost integrity. The ethical requirements of honesty, competence, respect for the individual, evidentiality, anonymity were set forth to the respondents, as well as to the questionnaires applied when answering the question why each respondent's personal data were encoded. In such a way we succeeded in achieving the ultimate truthful responses. The objectivity and impartiality of the study results is doubtless.

The experimental verification of the motivational potential of the study visits method was carried out by diagnosing the level of motivation for the future professional activity of EG students. The diagnostic procedure was performed twice: at the beginning of the semester (before the use of study visits) and at the end of the study semester (after their conducting) using the Rean method [22], adapted by the author. The adaptation consisted in the selection of questions related to professional intentions, as well as their specification regarding choreography as the students' future professional activity. In total, 10 statement questions were formulated, which were evaluated on a five-point Likert scale (from 1 to 5), where 1 point corresponded to the lowest and 5 points - to the highest manifestation of the corresponding motive: 1. I study because I like the profession of choreographer. 2 . I study to ensure the success of future professional activities as a choreographer. 3 . I study to give answers to relevant questions in the field of choreography. 4. I want to make full use of my inherent talents, abilities and inclinations to the chosen profession of a choreographer. 5. I like developing synopsis plans of choreography classes. 6. I like selecting the methods of teaching choreography. 7. I like improving my skills as a choreographer. 8. I like conducting choreography classes. 9. I like to searching for engaging materials and exercises to motivate students to choreography. 10. I like evaluating students' choreography skills.

The results of the survey were summarized by translating the quantitative scale into a qualitative interval scale, in which according to the sum of points the answers were subdivided into four levels: low (10-20 points), below average (21-30 points), average (31-40 points) and high (41-50 points).

To determine the group homogeneity and changes in professional motivation indicators under the influence of experimental factors, the statistical criterion Pearson's $\chi^{2}$ (chisquare) was calculated.

The experiment also took into account the level of students' choreographic preparedness. The evaluation was carried out by an expert group, which included three experts from among the leading teachers of the Department of Choreography. Expert grades were adjusted in accordance with the grading system according to the ECTS scale from 0 to 100 points, which was translated into a qualitative four-level scale. That is, the number of points obtained in the range from 75 to 100 corresponded to a high level, 60-74 points - an average level, 36-59 - a sufficient level, from 1 to 35 points - a low level [23].

\section{RESULTS}

In the situation before the experiment, the alignment of the experimental and control groups of EG and CG students was performed (Table 1). 
Table 1. Comparison of EG and CG by demographic indicators and levels of choreographic training

\begin{tabular}{|c|c|c|c|c|c|c|c|c|c|}
\hline \multirow[t]{2}{*}{ Groups } & \multirow{2}{*}{ 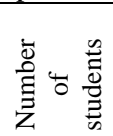 } & \multicolumn{2}{|c|}{ Age (years) } & \multicolumn{2}{|c|}{ Gender } & \multicolumn{4}{|c|}{ Levels of choreographic training } \\
\hline & & $19-22$ & $23-26$ & girls & boys & high & average & sufficient & low \\
\hline EG & 37 & 30 & 7 & 25 & 12 & 5 & 18 & 12 & 2 \\
\hline CG & 38 & 29 & 9 & 27 & 11 & 6 & 17 & 14 & 1 \\
\hline
\end{tabular}

The comparison of groups according to these indicators according to Table 1 indicates almost the same distribution of respondents by age (empirical value of the criterion $\chi 2 \mathrm{emp}=$ $0,254<\chi 2 \mathrm{cr}=3.841$ at the significance level of $\mathrm{p}<0.05)$, gender $(\chi 2 \mathrm{emp}=0.107<\chi 2 \mathrm{cr}=3.841, \mathrm{p}<0.05)$ and levels of choreographic training $(\chi 2 \mathrm{emp}=0.107<\chi 2 \mathrm{cr}=2.340, \mathrm{p}$ $<0.05)$.

Also, the diagnosis of professional motivation of EG and CG students was performed (Table 2).

Table 2. Professional motivation of EG and CG students (situation "before the experiment")

\begin{tabular}{|c|c|c|c|c|c|c|c|c|c|c|}
\hline \multirow{3}{*}{$\begin{array}{c}\text { Groups of } \\
\text { students }\end{array}$} & \multirow{3}{*}{$\begin{array}{l}\frac{0}{2} \\
\frac{0}{2} \\
2\end{array}$} & \multirow{3}{*}{$b^{\circ}$} & \multicolumn{8}{|c|}{ Levels of professional motivation } \\
\hline & & & \multicolumn{2}{|c|}{ high } & \multicolumn{2}{|c|}{ average } & \multicolumn{2}{|c|}{ below average } & \multicolumn{2}{|l|}{ low } \\
\hline & & & People & $\%$ & People & $\%$ & People & $\%$ & People & $\%$ \\
\hline EG & 37 & 100 & 5 & 14.0 & 18 & 49.0 & 12 & 32.0 & 2 & 5.0 \\
\hline $\mathrm{CG}$ & 38 & 100 & 6 & 16.0 & 17 & 44.0 & 14 & 37.0 & 1 & 3.0 \\
\hline
\end{tabular}

Visual analysis of Table 2 shows that a high level of professional motivation is characteristic of students numbering from $14 \%$ (experimental group) to $16 \%$ (control group), the average level - from $44 \%$ (CG) to $49 \%$ (EG), from $32 \%$ (EG) to $37 \%$ (CG) of students have a level below average, and from $3 \%$ (CG) to 5\% (EG) showed a low level. So, the difference between the shares of students by levels of professional motivation is from $2 \%$ to $5 \%$, which is within the statistical error. Statistical analysis of the data in Table 2 showed that the empirical value of $\chi 2$ criterion is 0.593 , whereas the critical value of this criterion at a significance level of $\mathrm{p}<0.05$ comprises 7.815. Thus, we can conclude that between the experimental and control groups there were no significant statistical differences in terms of the professional motivation level.

The experimental work consisted in the organization of study visits, which took place in the form of master classes conducted by such outstanding artists as the People's Artist of Ukraine, G.M Chapkis; Head of the Choreography Department of the Lithuanian Academy of Music and Theater, Professor V. Matsiulskis; world-famous director, chief choreographer of the world show production companies S. Ruchynsky; the semifinalists of the World Championship on the European program O. Guzyr and R. Otto; world-famous hip-hopper, founder of the "Chapkis Dance" Greg Chapkis; the leader and chief choreographer of the dance group "Forsythe", silver medalist of the project " Dance All " O. Leshchenko; the founder of the school of air choreography "Tata Art Hangar" E. Kit; thewinner of the project "Dancing with the Stars", finalist of the TV project "Everybody Dances - 2!" I. Gvozdiova; n'Era Dance Group founders V. Detyuchenko and
B. Kyrylenko; renowned choreographers and producers A. Stetsky and O. Turaeva and others.

During each visit, students analyzed the lessons in their essays, highlighted the relevance, novelty and practicality of the proposed material, considered the scope of its application, evaluated the innovative approach to the master class and the personal touch of the choreographer's style of presenting a new material and students' coming to grips with it. Moreover, students described the methods used by the author during the master class, also paying attention to the emotional background and the degree of interest of those attending the class. Writing down their impressions, they gave an overall assessment of the master class in which they participated, as well as drew conclusions, formulated comments, recommendations and suggestions.

Analyzing the students' essays, we registered the main impressions about the master classes they attended and about the methods of study visits in general: "We got acquainted with new dance styles", "We had the opportunity to learn new techniques and improve our performing skills", "Got the inspiration impulse and motivation for the success of our own", "Master classes are always emotionally charged, energizing, boosting the spirits and are a great way to get a drive in choreography classes", "Such classes provide an opportunity to walk out of comfort zone and get closer to the higher level of skill, "We had the opportunity to receive valuable feedback and advice from the artists, to see our downsides through the eyes of experienced teachers".

After the experiment, a refresher review of professional motivation of students in the experimental and control groups was conducted (Table 3). 
Table 3. Professional motivation of EG and CG students (situation "after the experiment")

\begin{tabular}{|c|c|c|c|c|c|c|c|c|c|c|}
\hline \multirow{3}{*}{$\begin{array}{l}\text { Groups of } \\
\text { students }\end{array}$} & \multirow{3}{*}{$\begin{array}{l}\frac{0}{0} \\
\text { ¿ } \\
0\end{array}$} & \multirow{3}{*}{$b^{\circ}$} & \multicolumn{8}{|c|}{ Levels of professional motivation } \\
\hline & & & \multicolumn{2}{|c|}{ High } & \multicolumn{2}{|c|}{ Average } & \multicolumn{2}{|c|}{ Below average } & \multicolumn{2}{|c|}{ Low } \\
\hline & & & People & $\%$ & People & $\%$ & People & $\%$ & People & $\%$ \\
\hline EG & 37 & 100 & 15 & 40.0 & 18 & 49.0 & 4 & 11.0 & 0 & 0 \\
\hline CG & 38 & 100 & 7 & 18.0 & 17 & 44.0 & 13 & 35.0 & 1 & 3.0 \\
\hline
\end{tabular}

Comparing the results of diagnostics of students' professional motivation in the experimental and control groups after the experiment according to Table 3 shows a significant increase in the share of students with a high level of motivation in the experimental group $(40.0 \%)$ compared to the same indicator in the control group (18.0\%). At the same time, the shares of students with an average level remained unchanged (49\% - in the experimental group and $44.0 \%$ - in the control group). However, there was a significant decrease in the number of students (almost three times - from $32.0 \%$ to $11 \%$ ) with a below-average level of professional motivation in the experimental group, while the number of students with the same level in the control group remained almost unchanged (35\% vs. $37 \%$ ). We also observed a lack of students with a low level of motivation in the experimental group, while in the control group the number of such students did not change (3 $\%)$. These differences were confirmed by statistical analysis: the empirical value of the criterion $\chi 2$ is 8.691 , which exceeds the critical value of this indicator (7.815) at a significance level of $\mathrm{p}<0.05$. Hence, it can be argued that in the experimental group there was a significant increase in the number of students with a high level of professional motivation due to a decrease in the corresponding number with average and low levels of the diagnosed indicator, as shown in Figure 1.

After the experiment, the levels of choreographic training in the experimental and control groups were also given introspection analysis (Table 4).

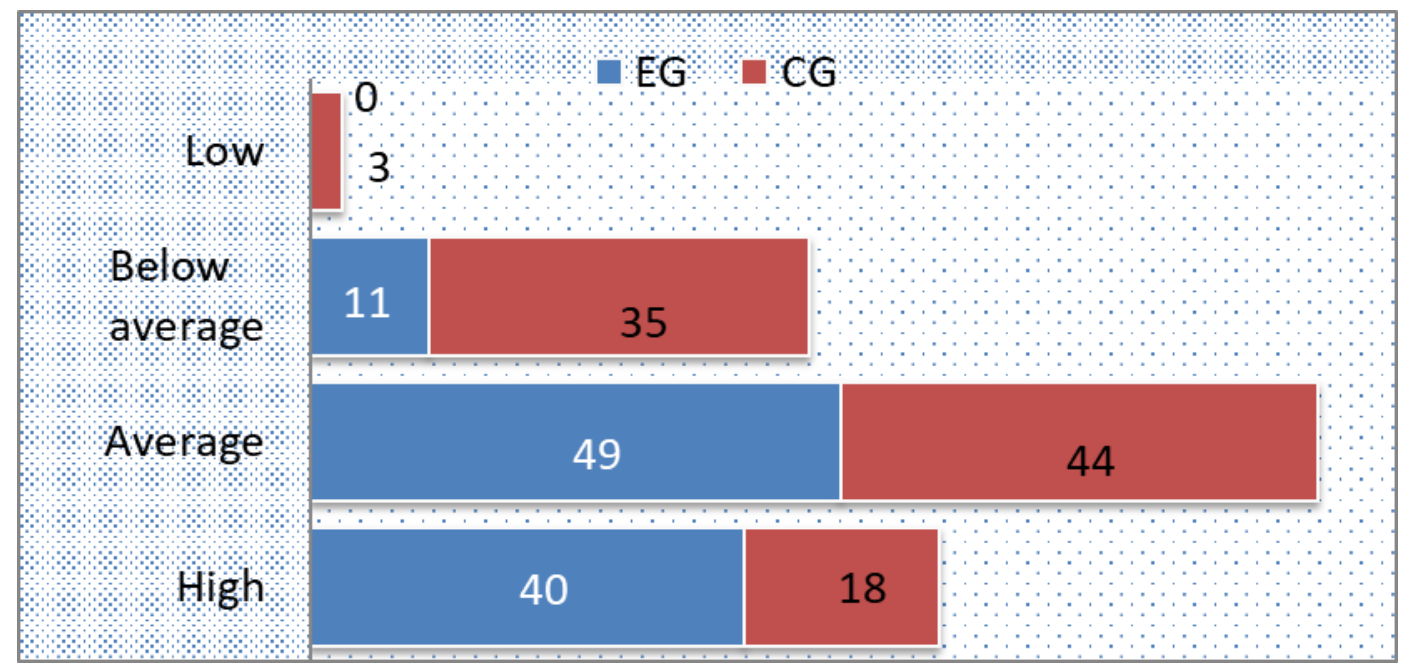

Fig. 1 Comparison of levels of professional motivation of students in EG and CG (situation 'after the experiment'), in\%

Table 4. Levels of choreographic training of students of EG and CG (situation "after the experiment")

\begin{tabular}{|c|c|c|c|c|c|c|c|c|c|c|}
\hline \multirow{3}{*}{$\begin{array}{c}\text { Groups of } \\
\text { students }\end{array}$} & \multirow{3}{*}{$\begin{array}{l}\frac{0}{2} \\
\frac{0}{0} \\
0\end{array}$} & \multirow{3}{*}{8} & \multicolumn{8}{|c|}{ Levels of choreographic training } \\
\hline & & & \multicolumn{2}{|c|}{ high } & \multicolumn{2}{|c|}{ average } & \multicolumn{2}{|c|}{ sufficient } & \multicolumn{2}{|c|}{ low } \\
\hline & & & People & $\%$ & People & $\%$ & People & $\%$ & People & $\%$ \\
\hline EG & 37 & 100 & 10 & 27.0 & 18 & 49.0 & 9 & 24.0 & 0 & 0 \\
\hline CG & 38 & 100 & 6 & 16.0 & 17 & 44.0 & 14 & 37.0 & 1 & 3.0 \\
\hline
\end{tabular}

The review of the data provided in Table 4 gives ground to take into consideration the differences between the data of the experimental and control groups, namely: the number of students with a high level of training in the experimental group exceeds by $11 \%$ the number of students in the control group, while the number of students with a sufficient level prevails by $13 \%$ in the control group. Despite the fact that the share of students with an average level in both groups did not change. That is, there is every ground to believe that as a result of the experiment, the level of students' choreographic training in the experimental group increased significantly. Though no statistical discrepancy between the data of the two groups was recorded (empirical value of the criterion $\chi 2 \mathrm{emp}=3.103 \mathrm{p}$ $\left.<0.05 \chi^{2 \mathrm{cr}}=7.815\right)$, the tendency to improve the 
choreographic training of students in the experimental group is evident.

In this regard, it is expedient to follow the changes in the level of choreographic training in the experimental group under the influence of the experimental factor. With this in mind, we present the relevant EG data before and after the experiment (Table 5).

Table 5. Changes in the levels of choreographic training of EG students as a result of the experiment

\begin{tabular}{|c|c|c|c|c|c|c|c|c|c|c|}
\hline \multirow{3}{*}{$\begin{array}{l}\text { Groups of } \\
\text { students }\end{array}$} & \multirow{3}{*}{$\begin{array}{l}\frac{0}{2} \\
\text { 足 } \\
\text { 2. }\end{array}$} & \multirow{3}{*}{$b^{0}$} & \multicolumn{8}{|c|}{ Levels of choreographic training } \\
\hline & & & \multicolumn{2}{|c|}{ low } & \multicolumn{2}{|l|}{ average } & \multicolumn{2}{|c|}{ sufficient } & \multicolumn{2}{|c|}{ low } \\
\hline & & & People & $\%$ & People & $\%$ & People & $\%$ & People & $\%$ \\
\hline $\begin{array}{c}\text { EG (before the } \\
\text { experiment) }\end{array}$ & 37 & 100 & 5 & 13.5 & 18 & 49.0 & 12 & 32.0 & 2 & 5.5 \\
\hline $\begin{array}{l}\text { EG (after the } \\
\text { experiment) }\end{array}$ & 37 & 100 & 10 & 27.0 & 18 & 49.0 & 9 & 24.0 & 0 & 0 \\
\hline
\end{tabular}

Visual analysis of Table 5 gives grounds to take into account the fact that after the experiment in this group the number of students with a high level of choreographic training doubled from $5(13.5 \%)$ to $10(27 \%)$ people. Also, the number of people with a sufficient level noticeably decreased: from $12(32 \%)$ to $9(24 \%)$, while the number of students with an average level remained unchanged - 18 (49\%). Such changes are take place in view of a more detailed analysis of the the studied indicator dynamics. The doubling of high-level students was due to an increase in the level from intermediate to high that was observed in five students. Also, five students who had a sufficient level succeeded in raising it to the medium, and two students raised their level from low to sufficient. A graphical presentation of the changes that occurred as a result of the experiment is shown in Figure 2.

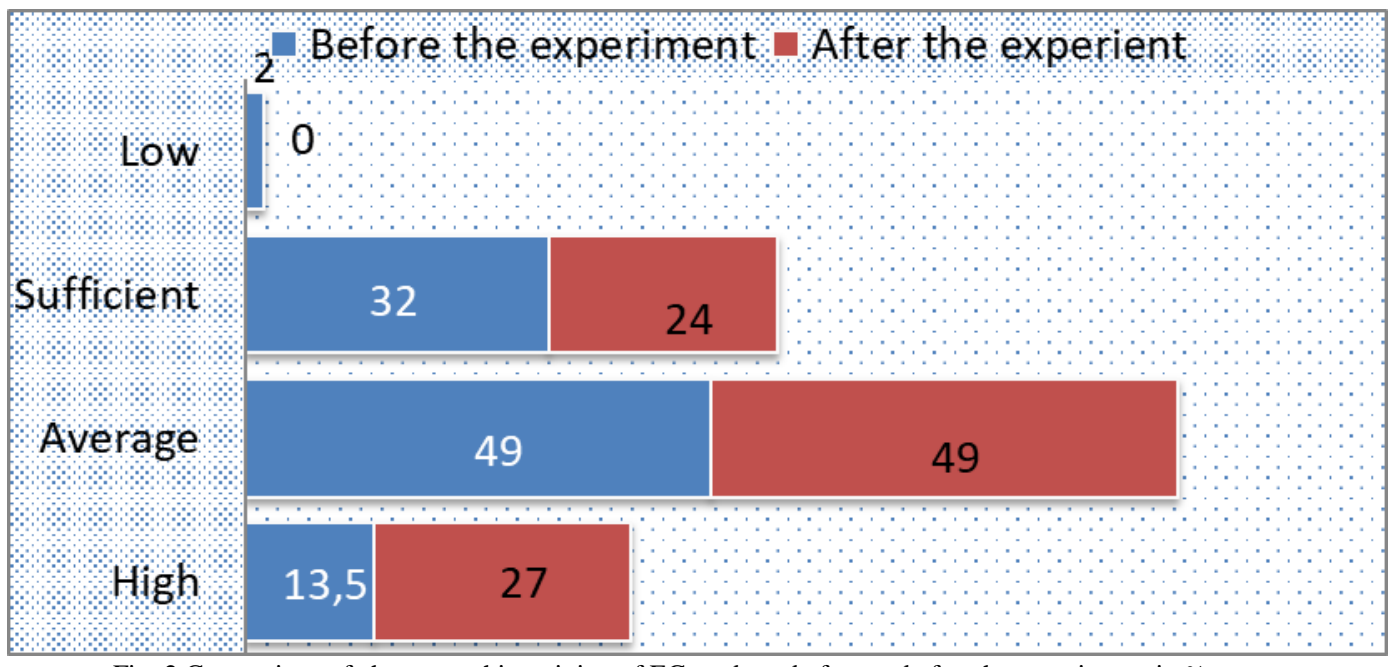

Fig. 2 Comparison of choreographic training of EG students before and after the experiment, in \%

We noted that the levels of choreographic training of students were characterized by certain qualitative features. Thus, students with a high level demonstrated the created compositions with excellent technics and high quality, performed on stage the choreographic vocabulary correctly with due regard to methodology. The said students emotionally conveyed the image, using the means of stage expression. They performed movements clearly and confidently in harmonious combination with the musical material. The average level referred to the students who prepared wellcreated compositions, but demonstrated plastic motives, made minor methodological and technical mistakes, performed dance movements rhythmically in combination with musical material. A sufficient level was demonstrated by the students who prepared compositions that had an integral structure, but were characterized by some methodological and technical downsides when performing the combinations. The students with a low level performed the created compositions at an insufficient level. Certain gross errors were made when performing combinations that do not reproduce the tasks

Further, one of the important research objectives was to determine the effect of professional motivation on the level of choreographic training of students. To verify the hypothesis of the presence or absence of such an effect, a correlation analysis of the table data was used, which includes the levels of professional motivation related to the levels of choreographic training of students in the experimental group in the after-experiment situation (Table 6). 
Table 6. Relationship between motivation and level of choreography training of EG students

\begin{tabular}{|c|c|c|c|c|c|}
\hline \multirow[b]{2}{*}{ Levels of professional motivation } & \multicolumn{4}{|c|}{ Levels of choreographic training } & \multirow[b]{2}{*}{ Tota } \\
\hline & $\begin{array}{l}\text { 点 } \\
\text { 王 }\end{array}$ & 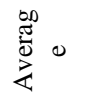 & 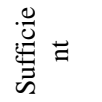 & 30 & \\
\hline High & 8 & 7 & 0 & 0 & 15 \\
\hline Average & 2 & 10 & 6 & 0 & 18 \\
\hline Below average & 0 & 1 & 3 & 0 & 4 \\
\hline Low & 0 & 0 & 0 & 0 & 0 \\
\hline Total & 10 & 18 & 9 & 0 & 37 \\
\hline
\end{tabular}

Pearson's correlation coefficient was used to calculate the relationship between the data in Table 5. As the introspection results in the group did not show a low level of professional motivation and a low level of choreographic training, cells with zero indicators were not taken into account. Calculations showed that the Pearson coefficient equals $\mathrm{P}=0.546$ and is statistically significant at the level of confidence probability $\mathrm{p}$ $<0.01(\chi 2 \mathrm{emp}=15.73 \mathrm{p}<0.01 \chi 2 \mathrm{cr}=13.277)$. Thus, the hypothesis that there is a connection between professional motivation and the level of students' choreographic training can be considered to be confirmed.

\section{DISCUSSION}

We presume that relevant to our study is an article by author [24], which aims to identify effective learning styles that foster creativity in future choreographers in South Korea. In particular, the researcher's attention is focused on the concept of fronesis, which the author views as a method of developing creativity and choreographic skills of students, based on the philosophy of Aristotle [24].

The article by author [25], which analyzes the problem of developing the foundations of future choreographers' professional mobility in the educational process of universities, to the fullest degree confirms the relevance and elaborates the content of our study, as it is through study visits that students have opportunities to learn and in such a way to develop their own professional mobility.

The formation of students' professional motivation essentially develops a positive image of the university - such a conclusion can be drawn from the study of author [26]. The authors experimentally proved that there is an impact of the Learning Management System (LMS) on the level of satisfaction and success of students which in turn helps to consolidate the branding of the university. This makes it possible to trace the relationships and interactions between study visits, student motivation and the image of the university, which enhances the importance of our research in the upgrowth of higher education, including choreography as a source of competitive advantage [26].

Study visits call the attention of multidisciplinary researchers. Thus, author's [27] article takes a close look at the experience of utilizing the teachers' study visits overseas. According to the author of the study, such visits promote the adaptation and acculturation of migrant teachers, and can also be used for the training before leaving abroad, for the deconstruction of transnational teachers and teaching experience.

The latest trends in the development of dance education are addressed in the article by author [28]. In particular, the author argues that on China's market of educational services choreographic online education is gaining its popularity. In our opinion, online classes have a significant potential for the application of study visits in choreographic education, as it provides an opportunity to engage in master classes the outstanding choreographers and teachers worldwide.

Proceeding from the findings of the study, it can be claimed that study visits are a very effective method of training future choreographers, as they increase the level of students' professional motivation of, and thus affect the development of their choreographic skills. In this case, we should pay attention to the psychological mechanism of transgression in the development of students' motivation for the choreographer's profession. Transgression is defined as the achievement by the subject of an external position in relation to something in the process of crossing borders and going beyond [29]. We see transgression as the key component of human creative activity aimed at revealing the uniqueness of the person and their aspirations. Understanding creativity as a transgression of the norm, we can reveal the new aspects of people's behavior and interaction in complex situations [30;31]. In this regard, noteworthy is the study of author [32], who considers dance as a way of aesthetic transgression of the body, as an expression of a healthy, pluralistic identity. In contrast to author [32], who used the concept of aesthetic transgression in relation to the audience, we look at it as a phenomenon of motivating choreography students under the influence of meetings with artists who made significant achievements in their professional activity. This view is confirmed in the study by author [33] drawing on interviews and observations by exemplary ballet teacher Minna Stanval at the Finnish National Opera Ballet School.

The theoretical implications of the study are the formation of a theoretical ground to ensure the motivation to teach future choreographers with the help of master classes. The purpose and content of master classes in the educational and professional training of future choreographers is being given a broader scale. The practical consequences of the study are to identify patterns of master classes' impact on instilling the future choreographers' training motivation as well as their professional motivation.

The overriding limitations of the study are the difficulty of 
identifying the study findings due to the limited sample of respondents. Another concern also lies in the elaboration and use of modern means of distance communication, the adequacy of the methods used for the research objective, taking into account the needs of the modern education system. Future research should encompass a larger sample of respondents and a wider range of questions. It is expedient to further investigate the stages of the future choreographers' motivation phenomenon.

\section{CONCLUSION}

While conducting the experimental research, the effectiveness of study visits for developing the motivation of future choreographers was proved. The experiment involved second-year students majoring in specialty 024 "Choreography. The experimental group (37 people) and control group (38 people) were formed by method of randomization. The experiment was carried out during the first semester of the 2019-2020 academic year and consisted of inviting well-known choreographers to conduct study visits involving the master classes with students of the experimental group. Students of the control group studied without the utilizing the study visits. The introspection of the resulting variable (that is, motivation for future professional activity) was carried out according to Rean's method, adjusted by the author to the needs of the current research. The method of content analysis of students' essays on the topic of the choreography professionals' visits was also used. Pearson's coefficient and $\chi 2$ Pearson's criterion were used to calculate the relationships between factor and result features, as well as to determine the statistical significance of the obtained data. The results of the experimental work showed a significant increase in motivation in the experimental group compared with the control group. Also with the help of correlation analysis (Pearson's correlation coefficient) the influence of increasing motivation on increasing the level of students' choreographic training was documented. The analysis of students' essays allowed ourlining the content of students' motivational intentions: improvement of the choreographic skills, gaining master's experience with the team, inspiration and motivation, awareness and work on their drawbacks, boosting their spirits, experiencing positive emotions, etc. In substantiating the results of the experiment, an assumption was put forth about the role of transgression as a phenomenon of forming the motivation of choreography students under the influence of meetings with artists, which calls for further research. That said, the study visits of choreography artists inspire students, play a facilitating role in overcoming the mundane, enrich their creative experience and offer a new look at the path to mastery in the art of choreography. Each meeting with a renowned personality who achieved outstanding results in choreography is considered by the students as an opportunity to go beyond the common and familiar, as an opportunity to understand and master new practices, new methods and knowledge, perform unconventional and creative tasks to meet the needs of self-realization and selfdevelopment. This process is basically accompanied by such feelings as the joy of improvisation, enlightenment and comprehension of the incomprehensible, hope for success, pride in person's own new achievement and excellence.

\section{References}

[1] J-Ph. Rivière, S. F. Alaoui, B. Caramiaux, and W. Mackay, How do dancers learn to dance? A first-person perspective of dance acquisition by expert contemporary dancers, 2018. Available: https://hal.archivesouvertes.fr/hal-01849604v2.

[2] D. M. McMahan, Training contemporary dancers: Exploring the relevance of classical modern dance technique. [Master's thesis], University of California, 2019.

[3] J. Diana, A 4-Step method to help your dancers learn choreography faster, Dance Teacher, 2017. Available: https://dance-teacher.com/making-it-stick/

[4] J. Roche, and A. Huddy, "Creative adaptations: integrating Feldenkrais principles in contemporary dance technique to facilitate the transition into tertiary dance education," Theatre, Dance Perform Train, vol. 6, no. 2, pp. 145-158, 2015. https://doi.org/10.1080/19443927.2015.1027452

[5] K. Höök, B. Caramiaux, C. Erkut, J. Forlizzi, N. Hajinejad, M. Haller, and H. Tobiasson, "Embracing first-person perspectives in soma-based design," Inform, vol. $5, \quad$ p. $\quad 8, \quad 2018$. https://doi.org/10.3390/informatics5010008.

[6] Abraham, A. Dunsky, and R. Dickstein, "The effect of motor imagery practice on elevé performance in adolescent female dance students: a randomized controlled trial," J Imag Res Sport Physic Activ, vol. 12, no. 1, 20160006, 2017. https://doi.org/10.1515/jirspa2016-000610.1515/jirspa-2016-0006

[7] K. Carey, A. Moran, and B. Rooney, "Learning choreography: an investigation of motor imagery, attentional effort, and expertise in modern dance," Front Psychol, vol. 10, art. no. 422, 2019. https://doi.org/10.3389/fpsyg.2019.00422

[8] J. Fisher, "Unfurling the wings of flight: clarifying 'the what'and 'the why'of mental i use in dance," Res Dance Educ, vol. 18, pp. 252-272, 2017. https://doi.org/10.1080/14647893.2017.1369508.

[9] M. Quinlan, "Gaga as Metatechnique: Negotiating Choreography, Improvisation, and Technique in a Neoliberal Dance Market," Dance Res J, vol. 49, no.2, pp.26-43,

2017. https://doi.org/10.1017/S0149767717000183

[10] M. Santos, "Instant Composition: choreographic training of the dance artist and his corporeality," Brazil J Presen Studies, vol. 8, no.1, pp. 167-193, 2018. http://dx.doi.org/10.1590/2237-266063624

[11] T. O. Izim, Z. U. Kaiyr, B. Turgymbaeva, M. S. Saukhanova, K. U. Kariyeva, Zh. M. Baigozhina, and A. 
Ahmuldinova, "On the professional competence formation in students as future choreography teachers (based on the art history materials of choreography of Kazakhstan)," Rev ESP, vol. 39, no. 21, pp. 38-47, 2018. http://www.revistaespacios.com/a18v39n21/a18v39n21p 38.pdf

[12] O. Khendryk, "The pedagogical approaches of the contemporary dance training for choreography of the students of Ukrainian higher educational establishments". Cult Ukr, vol. 65, pp. 196-206, 2019. https://doi.org/10.31516/2410-5325.065.20

[13] B. Wenn, R. Mulholland, W. Timmons, and Y. Zanker, "Towards a developing construct in dance education exploring the relation of emotional intelligence to teacher's sense of efficacy and teaching experience among dance education student teachers in the United Kingdom," Res Dance Educ, vol. 19, no. 1, pp. 14-38, 2018. https://doi.org/10.1080/14647893.2017.1354843

[14] N. Rowe, R. Martin, and N. Giacaman, "Computer Coding and Choreography: Contrasting Experiences of Learning about Collaboration in Engineering and Creative Arts," Int J Learn, Teach Educ Res, vol. 19, no. 10, pp. 214-232, 2020. https://doi.org/10.26803/ijlter.19.10.12

[15] Y. You, "Online technologies in dance education (China and worldwide experience)," Res Dance Educ, 2020. Available: https://doi.org/10.1080/14647893.2020.1832979

[16] N. Seheda, H. Panchenko, L. Chervonska, and A. Uskova, "Developing Creative Abilities of Future Musical Art Teachers by Means of Choreography: An Experimental Study," J Hist Cult Art Res, vol.8, no. 2, pp. 293-300, 2019. http://dx.doi.org/10.7596/taksad.v8i2.2006

[17] A. Kimber, The choreography of the classroom: performance and embodiment in teaching [Unpublished doctoral dissertation], University of Illinois at UrbanaChampaign Submitted, 2016. Available: http://hdl.handle.net/2142/90528

[18] C. Carter, "Dance and Choreography as a Method of Inquiry," Forum Qual Soc Res, vol. 21, no. 3, Art. 9, 2020. http://dx.doi.org/10.17169/fqs-21.3.3448

[19] M. Dobbs, Dance master class: What is it, and how does it benefit me as a dancer? Metropolitan School of the Arts, 2017. Available: https://metropolitanarts.org/dancemaster-class-benefit-dancer/

[20] Northern School of Contemporary Dance, 2021. Available:https://www.nscd.ac.uk/courses/ba-honsdance-contemporary

[21] The University of Winchester. BA (Hons) Choreography and Dance, 2021. Available: http:// www.winchester.ac.uk/

[22] E. P. Ilyin, Motivation and motives. St. Petersburg, Piter, 2011.

[23] European Commission., "European Credit Transfer and Accumulation System". Available: https://ec.europa.eu/education/resources-and- tools/european-credit-transfer-and-accumulation-systemects_en

[24] N. Kim, "Identifying choreographic Phronesis teaching styles for creativity," Res Dance Educ. 2020. https://doi.org/10.1080/14647893.2020.1812560

[25] K. Azizkhanova, N. S. Almetov, S. Zh. Turdaliyeva, A. B. Aitzhanova, and G. M. Musakhanova, "Formation of Professional Mobility Basis of Future Choreographers in the Process of Studying at the University," J Talent Devel Excel, vol. 12, no. 1, pp. 590-608, 2020.

[26] S. Soegoto, U. Narimawati, and J. Saputra, "Does A Learning Management System Enhance University Branding Due to Student Satisfaction and Performance," J Talent Develop Excellence, vol. 12, no.1, pp. 10831098, 2020.

[27] R. C. Mizzi, "Bridging Borders: Toward a Pedagogy of Preparedness for Visiting Faculty," J Stud Int Educ, vol. 21, no. 3, pp. 246-260, 2017.https://doi.org/10.1177/1028315316687011

[28] T. O. Razumenko, (2020). "Dance education in China: analysis of offline and online trends," Theor method teach educ, vol. 49, pp. 80-87, 2020. https://doi.org/10.34142/23128046.2020.49.07.

[29] A. Gritsanov, The latest philosophical dictionary. Postmodernism. Minsk, Sovremennyi literator, 2007.

[30] K. Krasnukhina, "Creativity as a transgression of the norm," in, National element of creativity: time and transgression: collection of articles, H. E. Aliaev, and O. D. Masloboeva (Eds.), St. Petersburg: St. Petersburg State University of Economics, 2017, pp. 56-67.

[31] H. Pozdeeva, (2019). "Transgressive factors in the development of the educational environment of the university," Syst analysis design manag, vol. 1, no. XXIII, pp. 358-363, 2019.

[32] T. Kobierzycki, "The dance scene and the processes of the aesthetic transgression of the body," Transdyscyplinarne Studia Kult. Eduk., vol. 13, pp. 93114, 2018.

[33] J. Chua, "The influences of an exemplary ballet teacher on students' motivation: «The Finnish Way»," Res Dance Educ, vol. 18, no. 10, pp. 3-22, 2017. http://dx.doi.org/10.1080/14647893.2016.1178715.

\section{Creative Commons Attribution License 4.0 (Attribution 4.0 International, CC BY 4.0)}

This article is published under the terms of the Creative Commons Attribution License 4.0 https://creativecommons.org/licenses/by/4.0/deed.en_US 


\section{Appendix A}

The structure of master classes analysis

1. The name of the master class and its purpose.

2. The relevance of the proposed material (degree of novelty), its practical orientation (where and how it can be used).

3. Innovative approach to conducting the master class. Highlighting the individual style of presenting the new material by the choreographer.

4. Analysis of the methods used by the author of the master class to get acquainted with its content.

5. The audience's degree of interest in the information material, the level of its consolidation.

6. Reflections, impressions and perspectives of applying the materials of a master class for development of students' own choreographic skill.

7. Remarks, recommendations and suggestions for the revised master class. 